\title{
Decay of a High Arctic lake-ice cover: observations and modelling
}

\author{
RICHARD HERON \\ 605-3576 Peter Street, Windsor, Ontario N9C 17S, Canada \\ Ming-Ko Woo \\ Department of Geography, McMaster University, Hamilton, Ontario L8S 4K1, Canada
}

\begin{abstract}
The decay of a lake-ice cover in the Canadian High Arctic was studied for 2 years. Melt at the upper surface accounted for $75 \%$ of the decrease in ice thickness, while $25 \%$ occurred at the ice-water interface. An energy-balance model, incorporating density reduction due to internal ice melt, was used to simulate the decay of the ice cover. The overall performance of the model was satisfactory despite periods when computed results differed from the observed ice decay. Energy-balance calculations indicated that the absorption of shortwave radiation within the ice provided $52 \%$ of the melt energy while 33 and $15 \%$ came from the surface-energy balance and heat flux from the water.
\end{abstract}

\section{INTRODUCTION}

The decay of lake ice in spring is an important annual event that profoundly influences the physical, chemical, biological, hydrological and geomorphological processes operating in the lake (Carson and Hussey, 1960; Schindler and others, 1974; Alestalo, 1980; Adams, 1981). Lake-ice decay processes at the upper and lower surfaces and inside the ice cover, along with their controlling factors, have been described qualitatively by many authors (e.g. Barnes, 1960; Williams, 1965, 1968; Hobbie, 1973). Detailed assessments of their relative magnitudes are not available, especially for the ice cover of Arctic lakes.

Most ice-decay measurements consider only the change in total ice thickness (Shaw, 1965; Williams, 1968; Bilello, 1980) and only Scott and Ragotzkie (1961) separated the thickness decrease into upper- and lowersurface components. Internal melt and its effects on ice porosity and albedo have been noted in laboratory and field situations (Barnes, 1960; Knight, 1962; Hobbs, 1974) and attributed to the absorption of radiation. However, apart from Bolsenga (1981) and a few others, there has been little effort to examine the behaviour of shortwave radiation in melting fresh-water ice, which is unlike pure ice, winter ice or sea ice where large bodies of information exist.

The simplest approach to modelling the decay of lake ice is the degree-day method (Bilello, 1980; Ashton, 1983) which assumes that air temperature is a good indicator of the available energy and melt processes. The energy balance requires more data, but it deals with the energy exchanges in a more realistic manner and forms the basis of the more comprehensive lake- and river-ice growth and decay models (Wake and Rumer, 1979; Greene and
Outcalt, 1985). Although radiation attenuation in the ice cover was included in these models, it was used only to determine the temperature in the ice or water. The porosity changes caused by internal melt were ignored and arbitrary ice densities were used to calculate icethickness change. Internal melt was incorporated by Ashton (1985) whose goal was to simulate ice strength but not ice thickness.

For lakes in the High Arctic, the ice is generally $2 \mathrm{~m}$ thick and the ice-cover duration often exceeds 10 months. Few systematic observations of the ice-decay processes have been made and there is no comprehensive, energybalance modelling of these processes. To address these gaps in our information, the present study examines the ice-cover conditions and melt processes occurring on an Arctic lake during the decay period and models ice-cover ablation using an energy-balance approach.

\section{THEORY}

The growth, thermal regime and decay of a lake-ice cover are controlled by the energy balance of the ice cover:

$$
\frac{\mathrm{d} S}{\mathrm{~d} t}=Q_{\mathrm{I}}^{*}+Q_{\mathrm{H}}+Q_{\mathrm{E}}+Q_{\mathrm{P}}+Q_{\mathrm{W}}
$$

where $Q_{\mathrm{I}}^{*}$ is the radiation balance of the ice, $Q_{\mathrm{H}}$ and $Q_{\mathrm{E}}$ are the sensible- and latent-heat fluxes at the upper ice surface, $Q_{\mathrm{P}}$ is the heat added by precipitation, $Q_{\mathrm{W}}$ is the heat flux from the lake water to the bottom surface of the ice and $\mathrm{d} S / \mathrm{d} t$ is the change in heat storage in the ice due to temperature changes as well as the gain or loss of mass. To model ice decay, the energy balances must be determined for the zones where melt occurs, including (1) the air-ice interface, (2) the ice-water interface and 


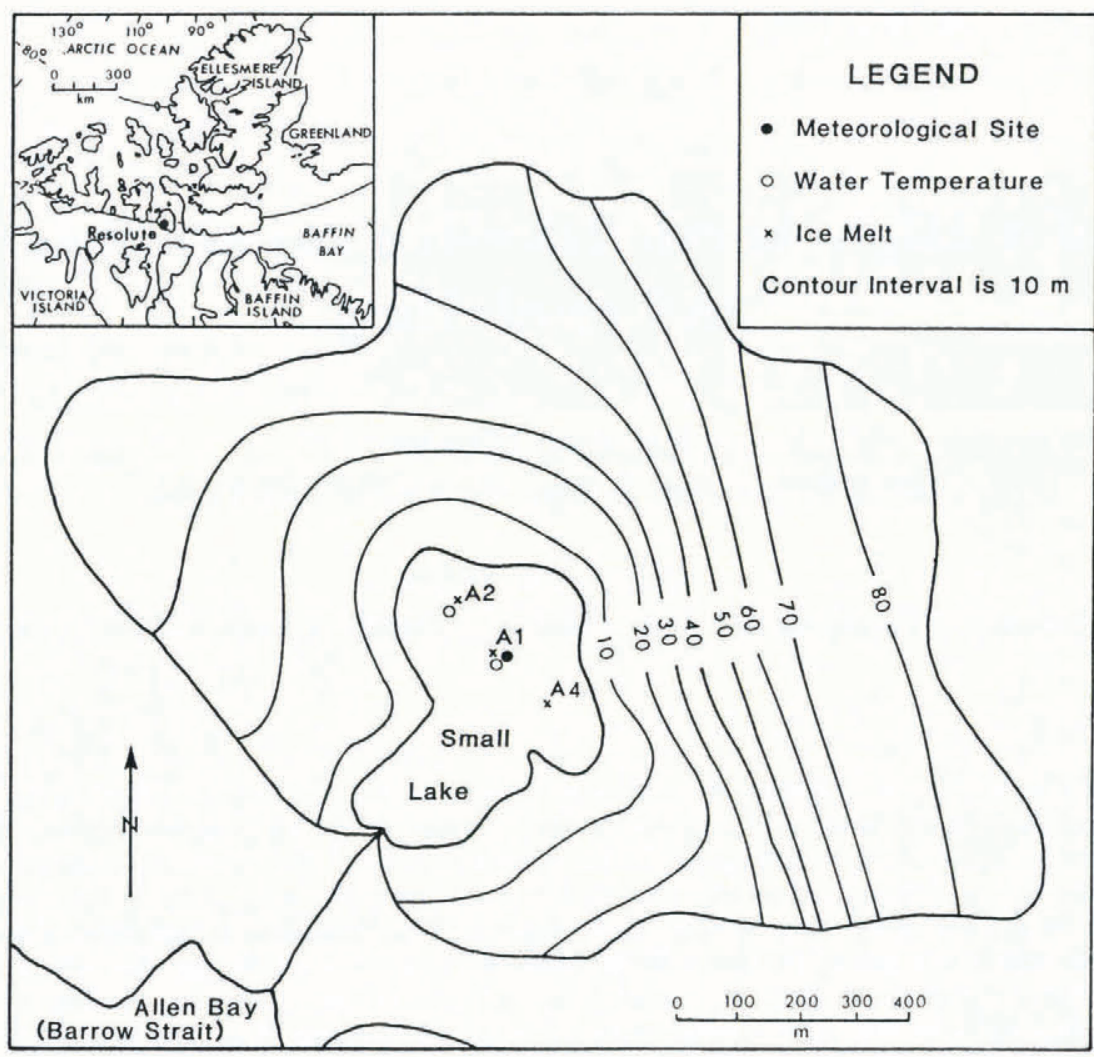

Fig. 1. Location of Small Lake near Resolute, N.W.T., Canada.

(3) the ice interior. In the discussion that follows, a positive flux is considered to be directed towards the ice.

The energy balance at the upper ice surface is

$$
L^{*}+Q_{\mathrm{H}}+Q_{\mathrm{E}}+Q_{\mathrm{P}}-Q_{\mathrm{MU}}-Q_{\mathrm{I}}=0
$$

where $L^{*}$ is the longwave radiation balance, $Q_{\mathrm{MU}}$ is the energy involved in surface melt and $Q_{\mathrm{I}}$ is the heat flux into the ice. The net longwave radiation can be considered as part of the surface-energy balance since the incident longwave radiation is rapidly absorbed by the ice. When the ice is isothermal at $0^{\circ} \mathrm{C}$ during melt, there is no heat conduction into the ice. Given the density of pure ice $\left(\rho_{\mathrm{pi}}\right)$ and the latent heat of fusion $\left(L_{\mathrm{F}}\right)$, the surface-melt rate $(\mathrm{d} h / \mathrm{d} t)_{\mathrm{US}}$ (in water-equivalent units) is

$$
(\mathrm{d} h / \mathrm{d} t)_{\mathrm{US}}=\frac{Q_{\mathrm{MU}}}{\rho_{\mathrm{pi}} L_{\mathrm{F}}}=\frac{L^{*}+Q_{\mathrm{H}}+Q_{\mathrm{E}}+Q_{\mathrm{P}}}{\rho_{\mathrm{pi}} L_{\mathrm{F}}} .
$$

The longwave-radiation balance may be obtained from the radiation balance of the ice surface:

$$
L^{*}=Q^{*}-\left(1-\alpha_{\mathrm{i}}\right) K \downarrow
$$

where $\alpha_{\mathrm{i}}$ is the shortwave albedo of the ice and $K \downarrow$ is the incident shortwave radiation.

Since the surface of the melting ice cover is fixed at $0^{\circ} \mathrm{C}$ and $100 \%$ relative humidity during the melt period, the aerodynamic bulk-transfer approach can be used to compute the fluxes of sensible and latent heat:

$$
\begin{aligned}
& Q_{\mathrm{H}}=\rho_{\mathrm{a}} C_{\mathrm{a}} D_{\mathrm{H}} u_{z}\left(T_{z}-T_{\mathrm{s}}\right), \\
& Q_{\mathrm{E}}=\rho_{\mathrm{a}} L_{\mathrm{v}}(\epsilon / P) D_{\mathrm{E}} u_{z}\left(q_{z}-q_{\mathrm{s}}\right) .
\end{aligned}
$$

Here, $\rho_{\mathrm{a}}$ is air density, $C_{\mathrm{a}}$ is the heat capacity of the air, $L_{\mathrm{v}}$ is the latent heat of vaporization, $\epsilon$ is the ratio of the molecular weights of air and water, $P$ is air pressure, $u_{z}$ is the wind speed at height $z, T_{z}$ and $T_{\mathrm{s}}$ are the temperature at height $z$ and at the surface, while $q_{z}$ and $q_{8}$ are the vapour pressures at the same locations. The exchange coefficients, $D_{\mathrm{H}}$ and $D_{\mathrm{E}}$, are assumed equal and are obtained from

$$
D_{\mathrm{H}}=D_{\mathrm{E}}=D=\frac{K^{2}}{\ln \left(z / z_{0}\right)^{2}}
$$

where $K$ is von Karman's constant. The surface roughness, $z_{0}$, can be estimated from the following equation under neutral atmospheric conditions:

$$
z_{0}=\exp \left(\frac{u_{2} \ln z_{1}-u_{1} \ln z_{2}}{u_{2}-u_{1}}\right)
$$

where $z_{1}$ and $z_{2}$ refer to the heights at which the wind speeds, $u_{1}$ and $u_{2}$, were obtained.

The exchange coefficients should be modified when applied to stable boundary layers overlying melting ice. This can be achieved through the Richardson number (Ri), defined as

$$
\mathrm{Ri}=g z \frac{T_{z}-T_{\mathrm{s}}}{T_{z}\left(u_{z}-u_{\mathrm{s}}\right)^{2}}
$$

where $g$ is the acceleration due to gravity. Under stable conditions when Ri $>0$, Price and Dunne, (1976) gave the exchange coefficient as

$$
D_{\mathrm{s}}=\frac{D}{1+b \mathrm{Ri}}
$$

and for unstable boundary layers $(\mathrm{Ri}<0)$

$$
D_{\text {us }}=\frac{D}{1-b \mathrm{Ri}}
$$


where $b$ is a coefficient with a value of 10 (Price and Dunne, 1976).

The final term to be estimated in Equation (4) is the heat brought to the surface by rainfall:

$$
Q_{\mathrm{P}}=\rho_{w} C_{\mathrm{w}} R\left(T_{\mathrm{p}}-T_{\mathrm{s}}\right)
$$

where $\rho_{\mathrm{w}}$ is water density, $C_{\mathrm{w}}$ is the specific heat of water, $T_{\mathrm{p}}$ is the rain temperature which is approximated by the wet-bulb temperature and $R$ is the rainfall intensity.

The energy balance at the bottom of the ice cover is

$$
Q_{\mathrm{ML}}=Q_{\mathrm{W}}-Q_{\mathrm{I}}
$$

where $Q_{\mathrm{I}}$ is the heat conducted upward into the ice and $Q_{\mathrm{ML}}$ is the heat used to melt the underside of the ice. During the melt period, $Q_{\mathrm{I}}=0$ since the ice is isothermal. Then, the melt rate at the lower ice surface $(\mathrm{d} h / \mathrm{d} t)_{\mathrm{LS}}$ (in water equivalent units) is

$$
(\mathrm{d} h / \mathrm{d} t)_{\mathrm{LS}}=\frac{Q_{\mathrm{W}}}{\rho_{\mathrm{pi}} L_{\mathrm{F}}} .
$$

The heat flux from the water is determined by the temperature gradient at the ice-water interface but, for operational purposes, this can be approximated by

$$
Q_{\mathrm{W}}=k_{\mathrm{w}} \frac{T_{z w}}{z w}
$$

where $k_{\mathrm{w}}$ is the thermal conductivity of water $\left(0.586 \mathrm{~W} \mathrm{~m}^{-1} \mathrm{~K}^{-1}\right.$ in still water) and $T_{z w}$ is the water temperature at a distance $z w$ from the ice-water interface.

Since the ice cover is isothermal during the decay period, thermal conduction can be ignored and the condition of the ice interior will be determined by absorbed solar radiation. The Bouguer-Lambert law describes the attenuation of radiation as it penetrates any medium:

$$
I_{z i}=I_{\mathrm{s}} \exp (-e \cdot z i) .
$$

Here, $I_{8}$ and $I_{z i}$ are the irradiances at the surface and at depth $z i$, while $e$ is the extinction coefficient describing the rate of the attenuation. The internal melt rate of the ice cover $(\mathrm{d} h / \mathrm{d} t)_{\mathrm{IN}}$ is then obtained as

$$
(\mathrm{d} h / \mathrm{d} t)_{\mathrm{IN}}=\frac{\left(1-\alpha_{\mathrm{i}}\right) K \downarrow 1-\exp (-e \cdot H)}{\rho_{\mathrm{pi}} L_{\mathrm{F}}}
$$

where $H$ is the ice-cover thickness.

Total ice-melt rate ( $\mathrm{d} h / \mathrm{d} t$, in water-equivalent units) is the sum of the three melt components

$$
\mathrm{d} h / \mathrm{d} t=(\mathrm{d} h / \mathrm{d} t)_{\mathrm{US}}+(\mathrm{d} h / \mathrm{d} t)_{\mathrm{LS}}+(\mathrm{d} h / \mathrm{d} t)_{\mathrm{IN}} .
$$

\section{STUDY SITE AND FIELD METHODS}

The study was carried out at Small Lake, about $5 \mathrm{~km}$ north of Resolute, Cornwallis Island, N.W.T., Canada (Fig. 1). The lake lies along the coast at an altitude of $5 \mathrm{~m}$ a.s.l., has an area of $0.15 \mathrm{~km}^{2}$ and a maximum depth of $10 \mathrm{~m}$. East of the lake is a steep slope which rises to $90 \mathrm{~m}$ a.s.l. and the rest of the catchment topography is gently rolling. The lake outlet is dammed by snowdrifts for the first 3-4 weeks of the decay period, causing the lake level to rise about $1 \mathrm{~m}$ before it drains (Woo and others, 1981).
An experimental site was established on the ice on the northeastern section of the lake where it is deep and a minimum fetch of about $140 \mathrm{~m}$ could be maintained. Measurements began when the ice started to melt and ended when the ice cover was about $0.5 \mathrm{~m}$ thick and fragmentation began. Air temperature and humidity were recorded on a hygrothermograph at $1 \mathrm{~m}$ above the ice. A net radiometer, a pyranometer for reflected shortwave radiation and a sensitive three-cup anemometer were set up nearby, and their outputs were recorded on strip-chart recorders. Air pressure, solar radiation and supplementary data to estimate missing values were obtained from the Atmospheric Environment Service weather station at Resolute Airport located $5 \mathrm{~km}$ away.

Manual measurements of the water-temperature profile beneath the ice were made daily with a thermistor array supported against the ice cover by a float for accurate placement. Manual albedo measurements using the pyranometer were made near mid-day, as were measurements of radiation attenuation in ice. A photocell with a $200 \mathrm{~nm}$ spectral range centred on $615 \mathrm{~nm}$ and calibrated against the pyranometer was used for this purpose. Ice density was obtained by removing a measured volume of ice and weighing it on a triplebeam balance. The surface roughness of the ice $\left(z_{0}\right)$ was calculated from wind-speed profiles using up to six anemometers to a maximum height of $2.5 \mathrm{~m}$ above the ice surface. These last three items were obtained at irregular time intervals.

Ice thickness, ablation of the upper-ice surface and icebottom melt were measured daily. A reference datum at the melt site was provided by a Plexiglass tube, fitted with Plexiglass collars to prevent vertical movement, that was frozen into the ice cover before melt. A flexible board was placed on the ice to mark the average position of the ice surface. The vertical distance from the board to the top of the reference Plexiglass stake was measured to provide surface ablation.

Ice thickness was obtained as close to the ablation stakes as possible. A measurement device, consisting of a metal tube with wooden blocks at either end, was hung horizontally beneath the ice on two resistance wires that could be heated if necessary (Ramseier and Weaver, 1975). The whole assembly was then raised with a handle until the blocks touched the lower ice surface. A change in ice thickness was determined by noting the change in the distance between the handle and upper ice surface, as given by the board. The amount of melt at the ice bottom was the difference between the change in ice thickness and the surface ablation. The water level beneath the ice surface, representing the hydrostatic water level, was measured with reference to the Plexiglass ablation stake.

\section{ICE-DECAY COMPUTATIONS}

The ice cover was divided into layers, $0.02 \mathrm{~m}$ thick, and calculations were conducted hourly. Since solar radiation was measured at the Resolute Airport weather station instead of directly over the lake ice, differences in cloud cover inevitably introduced variability into the data used to obtain short-term values of albedo and net longwave radiation. Daily values were calculated instead of averaging such variations. 


\section{Internal melt}

Hourly melt in the ice-cover interior was calculated sequentially for each layer. The required extinction coefficients were obtained from Equation (16). For the surface layer, $I_{8}$ was set to $\left(1-\alpha_{\mathrm{i}}\right) K \downarrow$ and the calculated $I_{\mathrm{zi}}$ was the irradiance for the top of the second layer; this procedure was extended to the other layers in the ice profile. The average extinction coefficient for the entire ice cover decreased from 1.0 to $0.65 \mathrm{~m}^{-1}$ during the melt period, with $0.8 \mathrm{~m}^{-1}$ being a typical value. While these values are consistent with those reported by Goldman and others (1967) and Hobbie (1973), the average for the whole cover is of limited usefulness, because of the large changes in this coefficient within the ice. The mean value for the porous layer above the hydrostatic water level was $4.0 \mathrm{~m}^{-1}$ and this lies at the low end of the spectral coefficients in the $400-700 \mathrm{~nm}$ range obtained by Roulet (1981) $\left(5.0-12.0 \mathrm{~m}^{-1}\right.$ for frozen snow ice) and Bolsenga (1980) $\left(4.8-5.2 \mathrm{~m}^{-1}\right.$ for frozen brash ice).

The extinction coefficient in the ice below the water level averaged $0.3 \mathrm{~m}^{-1}$, a value smaller than Bolsenga's (1978) $\left(0.6-0.8 \mathrm{~m}^{-1}\right.$ for melting black ice with surface water) but consistent with the laboratory results of Irvine and Pollack (1968) and Grenfell and Perovich (1981) for pure, cold ice in the spectral region of the photocells used in this study. This suggests that the lower part of a melting lake-ice cover behaves like solid ice.

The wavelength band covered by the extinction coefficient obtained in this study for the surface-ice layer was too narrow to be representative of bulk extinction coefficient for the wavelengths $(400-1400 \mathrm{~nm})$ containing most of the shortwave radiation. For the surface layer of melting sea ice, Grenfell and Maykut (1977) obtained bulk extinction coefficients of $10.5 \mathrm{~m}^{-1}$ for clear skies and $17.1 \mathrm{~m}^{-1}$ when overcast, with an average of $13.8 \mathrm{~m}^{-1}$. The spectral extinction coefficients for the melting sea ice in the same spectral region covered by the photocell varied from 5.5 to $14 \mathrm{~m}^{-1}$, with an average roughly twice as large as the coefficient obtained in this study $\left(4 \mathrm{~m}^{-1}\right)$. Assuming that the patterns of spectral attenuation for melting sea and lake ice are similar and that the ratio of their extinction coefficients does not vary greatly, the bulk extinction coefficient used in the model $\left(7 \mathrm{~m}^{-1}\right)$ was estimated by halving the average bulk-extinction coefficient for sea ice given above.

The bulk-extinction coefficient for the ice below the hydrostatic water level was estimated using the spectral coefficients $\left(e_{\lambda}\right)$ (Grenfell and Perovich, 1981), the spectral irradiances $\left(I_{\lambda}\right)$ and albedos $\left(\alpha_{\lambda}\right)$ (Grenfell and Perovich, 1984)

$$
e=\frac{\sum_{400}^{1400} e_{\lambda}\left(1-\alpha_{\lambda}\right) I_{\lambda} \Delta \lambda}{\sum_{400}^{1400}\left(1-\alpha_{\lambda}\right) I_{\lambda} \Delta \lambda}
$$

Here, $\lambda$ indicates the wavelength in the $400-1400 \mathrm{~nm}$ range. The bulk-extinction coefficient calculated in this manner varied from $0.5 \mathrm{~m}^{-1}$ near the ice surface to $0.14 \mathrm{~m}^{-1}$ at a depth of $2.4 \mathrm{~m}$. The mean value of $0.32 \mathrm{~m}^{-1}$ coincided with the observed extinction coefficient $\left(0.3 \mathrm{~m}^{-1}\right)$ and this value was used to describe the extinction of shortwave radiation in the ice below the hydrostatic water level.
To mimic the development of the porous surface layer by internal melt, the bulk-extinction coefficient was increased linearly from 0.3 to $7 \mathrm{~m}^{-1}$ during the first $5 \mathrm{~d}$. On a number of occasions late in the melt period, the highly porous layer melted quickly and the ice surface became dark and relatively transparent. To account for this, the extinction coefficient was set to $0.3 \mathrm{~m}^{-1}$ when the albedo decreased below 0.2 .

The hydrostatic water level is required to determine when an ice layer becomes part of the porous surface layer, so that the appropriate extinction coefficient can be applied. This was computed by balancing the buoyancy of lower ice layers against the weight of the surface layers. The buoyancy of an ice layer $(B$, expressed as mass per unit area) with thickness $(\Delta z i)$ is

$$
B=\Delta z i\left(\rho_{\mathrm{w}}-\left(\rho_{\mathrm{i}}+\frac{\rho_{\mathrm{pi}}-\rho_{\mathrm{i}}}{\rho_{\mathrm{pi}}} \rho_{\mathrm{w}}\right)\right)
$$

where $\rho_{\mathrm{w}}$ is the water density. The weight of the layer $(W)$ is

$$
W=\Delta z i \rho_{\mathrm{i}} .
$$

To locate the ice layer that contains the hydrostatic water level, the total values of $B$ and $W$ were compared layer by layer. The layer at which the accumulated weight was balanced by the buoyancy contains the hydrostatic water level, and the position of the water level within the layer was determined by linearly interpolating both weight and buoyancy.

The bulk density of the porous ice $\left(\rho_{\mathrm{i}}\right)$ in each layer was determined by adjusting the density of solid ice by the ratio of the energy accumulated within each layer to the energy needed to melt an equivalent layer of solid ice. At the beginning of the study period it was assumed that the ice density was that of pure ice $\left(917 \mathrm{~kg} \mathrm{~m}^{-3}\right)$.

\section{Surface and bottom melt}

To calculate the sensible- and latent-heat flux components of surface ice-melt energy, a value for the surface roughness $\left(z_{0}\right)$ is required. Using measurement periods of 5-15 min over a range of ice-surface conditions, a mean value of $4.5 \mathrm{~mm}$ with a standard deviation of $1.5 \mathrm{~mm}$ was obtained. This is much larger than $0.15 \mathrm{~mm}$ measured for winter ice by Lettau (1969) and $0.3 \mathrm{~mm}$ used by Greene and Outcalt (1985) for both ice growth and decay. It is comparable to the surface roughness of $2.46 \mathrm{~mm}$ for melting glacier ice (Munro, 1989) and is within the range of values for melting snow reported by Moore (1983).

Occasionally, the calculated surface-melt energy was negative when the longwave radiation loss from the surface offset the energy gained or if the air temperature fell below $0^{\circ} \mathrm{C}$. In such cases, this energy deficit was accumulated and no surface melt was permitted. The radiation absorbed by the top ice layer and any surface energy gained were used to satisfy the energy deficit before ice melt was resumed.

To calculate the ice-surface lowering, the radiation absorbed was first used to determine internal melting and the new ice-density profile. Other sources of energy were computed using Equation (3) and the total melt energy was converted into ice melt. On the underside of the ice cover, the decrease in ice thickness was computed using 
Equation (14). In both equations, $\rho_{\mathrm{i}}$ of the interfacial layer was substituted for $\rho_{\mathrm{pi}}$.

\section{FIELD MEASUREMENTS}

Ice-melt conditions in 1980 were similar to those in 1981. Since the 1981 data is of better quality, these results will be emphasized in the following discussion.

\section{Meteorological conditions}

Immediately before ice melt, snow melt started when air temperatures rose to the freezing point. The temperatures within the floating ice also increased and within one week, the ice was isothermal at $0^{\circ} \mathrm{C}$ and the research site was almost free of snow (Fig. 2). This marked the beginning of the study period.

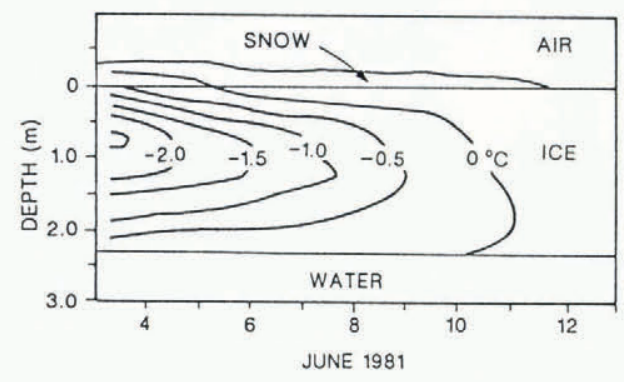

Fig. 2. Ice-cover thermal conditions at the beginning of the study period, 1981.

The meteorological conditions for the 1981 ice-melt period are indicated in Figure 3. At the beginning of the melt season, negative net radiation occurred only briefly, when the solar elevation was low. As melt advanced and

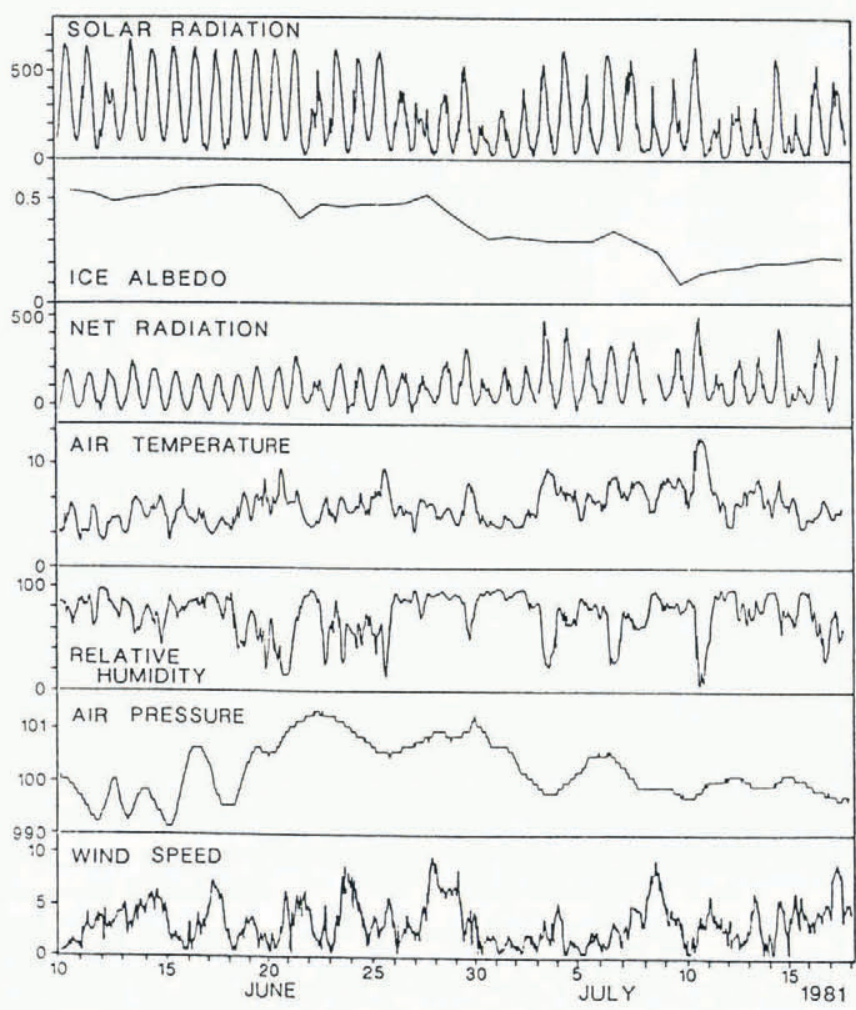

Fig. 3. Meteorological conditions during the 1981 study period. the ice albedo decreased, the net radiation was positive throughout the $24 \mathrm{~h}$ days. Air temperature increased after the melt began as the ground surrounding the lake became bare of snow. Maximum daily temperatures occasionally exceeded $10^{\circ} \mathrm{C}$ and the minimum rarely fell below freezing. Air temperature and relative humidity fluctuated considerably, depending on whether the wind blew onshore from the cold sea ice or from the warmer bare ground.

\section{Water temperature}

Water temperatures measured in Small Lake (Fig. 4) were similar to those reported for other Arctic lakes (Schindler and others, 1974). Most of the lake water was isothermal and subject to vertical mixing but, once melt started, a stable layer of meltwater began to accumulate immediately beneath the ice cover. A reduction in the dissolved solids, as indicated by the low specific conductance values in Figure 4, enhanced the stability.

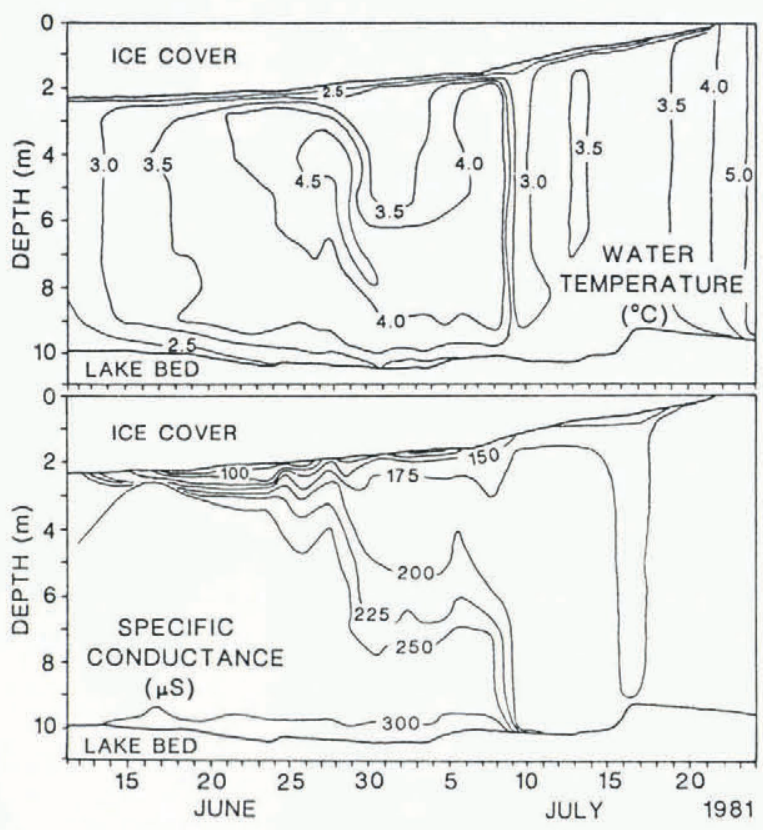

Fig. 4. Thermal conditions and specific conductance $(\mu S)$ of Small Lake. High specific conductance indicates a large dissolved solids content.

Water temperatures at the base of this layer reached $5.5^{\circ} \mathrm{C}$ approximately half-way through the 1980 icedecay period due to radiative heating of the water and possible influx of warm water of low specific conductance from the catchment. Vertical mixing induced by density differences and enhanced by wind-driven water soon weakened the stratification of water temperature and specific conductance. Stratification was eliminated 2 weeks before the end of the melt season.

Of particular importance to ice melt is the temperature gradient in the water layer just below the ice. Temperature measurements taken $0.05 \mathrm{~m}$ beneath the interface (Fig. 5) indicate that this gradient increased from 8 to $69^{\circ} \mathrm{C} \mathrm{m}^{-1}$ during the melt period. The marked increase in water temperature mid-way through the melt period in both years was due to increased radiant heating of the water below the thinning ice. 


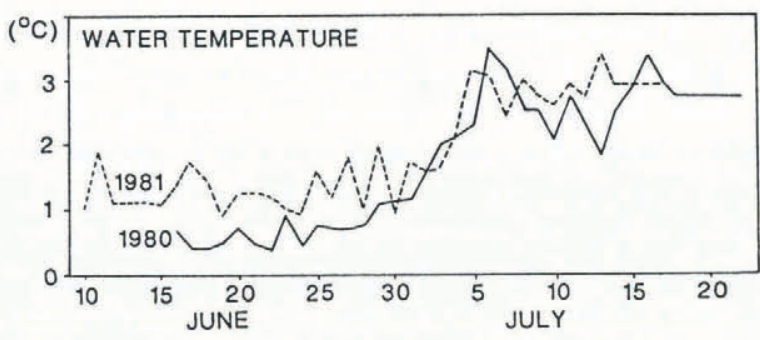

Fig. 5. Daily water temperatures $0.05 \mathrm{~m}$ beneath the bottom of the ice cover.

\section{Ice-cover conditions}

Wind scour during winter reduced the snow depth to under $0.2 \mathrm{~m}$ on most parts of the lake ice. The snow was $0.10-0.15 \mathrm{~m}$ thick at the study sites. During the snow-melt phase, this snow cover yielded up to a centimeter of basal ice when the meltwater refroze on the cold ice (Woo and Heron, 1981).

At the centre of the lake, where the study was conducted, the ice was typically $2.3 \mathrm{~m}$ thick. The ice crystals at the surface had essentially vertical $c$-axes and diameters of about $10 \mathrm{~mm}$. Due to the wedging-out process described by Perry and Pounder (1958), these crystals were gradually replaced between 0.3 and $0.5 \mathrm{~m}$ depth by ice with horizontal $c$-axes (no preferred orientation) and a vertical $a$-axis basal plane. This orientation continued to the ice bottom where the icecrystal diameters reached $0.8 \mathrm{~m}$.

\section{Ice-thickness decrease}

\section{Surface ablation}

Measured ice-surface ablation rates for three sites are plotted in Figure 6. Initially, the rate of lowering was

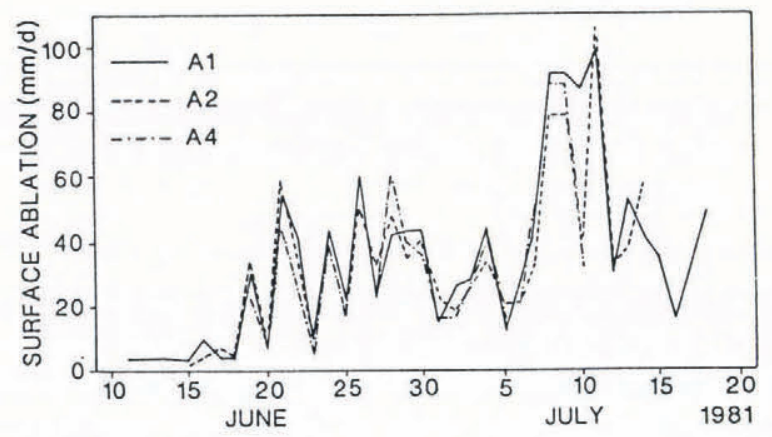

Fig. 6. Daily ice-ablation rate at the upper ice surface of Small Lake, 1981.

small but, once surface-ice density decreased, additional melt energy increased the rate of surface lowering, peaking at $106 \mathrm{~mm} \mathrm{~d}^{-1}$ late in the melt period. Variability of daily ablation rates among three sites reflects not only measurement error but differences in ice conditions at each ablation stake. On a daily basis, the measured differences were usually less than $30 \%$ but, over the melt period, differences in total ablation for these three sites was only $5 \%$.
The cumulative surface ablation at site $\mathrm{Al}$ in 1980 was $1.13 \mathrm{~m}$ or $58 \%$ of the ice-thickness loss. Because of slippage by the ablation stakes in 1980, surface ablation was underestimated. A more realistic value of $75 \%$ was obtained in 1981, when $1.24 \mathrm{~m}$ of ablation occurred (Fig. 7).

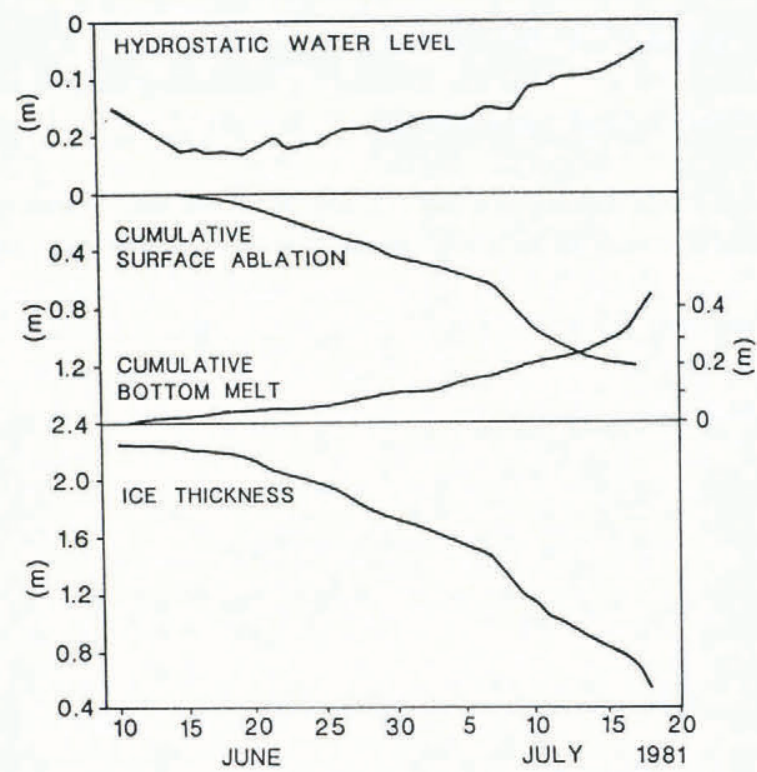

Fig. 7. Ice thickness, cumulative surface ablation and bottom melt, and hydrostatic water level at the research site, 1981.

\section{Bottom melt}

Ice melt at the bottom of the ice cover in the first half of the melt period was typically $2 \mathrm{~mm} \mathrm{~d}^{-1}$ but individual values fluctuated greatly. Since it was obtained as the difference between change in ice thickness and surface ablation, the cumulative measurement error of these two other variables may exceed the bottom melt itself. When the average melt rate increased to $6.4 \mathrm{~mm} \mathrm{~d}^{-1}$ in the middle of the study period and to $13.0 \mathrm{~mm} \mathrm{~d}^{-1}$ near the end, the residual error diminished. The greatest daily loss of ice from the bottom $(120 \mathrm{~mm})$ occurred on the last day of measurement and was due to currents, vertical mixing of the water and ice movement. During the 1981 study period, $0.33 \mathrm{~m}$ of melt occurred from the bottom of the ice cover, $0.45 \mathrm{~m}$ if the last day is also included (Fig. 7).

The 1980 ice-bottom melt was similar to those for 1981 except for $2 \mathrm{~d}$ of rapid melt that averaged $195 \mathrm{~mm} \mathrm{~d}^{-1}$. Consequently, the total bottom melt in 1980 was $0.81 \mathrm{~m}$, more than twice the 1981 value. Some of this difference can be attributed to slippage by the ablation stakes which provided the reference datum in 1980.

\section{Internal melt}

Ice melt above the water level produced an extremely porous layer during the first week of decay. Ice-crystal boundaries melted and the ice cover had a relatively uniform surface with a foam-like appearance due to the small pores in the crystals. When crystal orientation changed from $c$-axis vertical to $c$-axis horizontal, the pores became larger and preferential melt of some of the ice-crystal basal planes roughened the ice surface. 
Ice-density profiles obtained during the initial melt period (Fig. 8) showed that internal melt was most intense near the surface. Surface-ice density decreased as internal melt progressed until densities fell below $100 \mathrm{~kg} \mathrm{~m}^{-3}$.

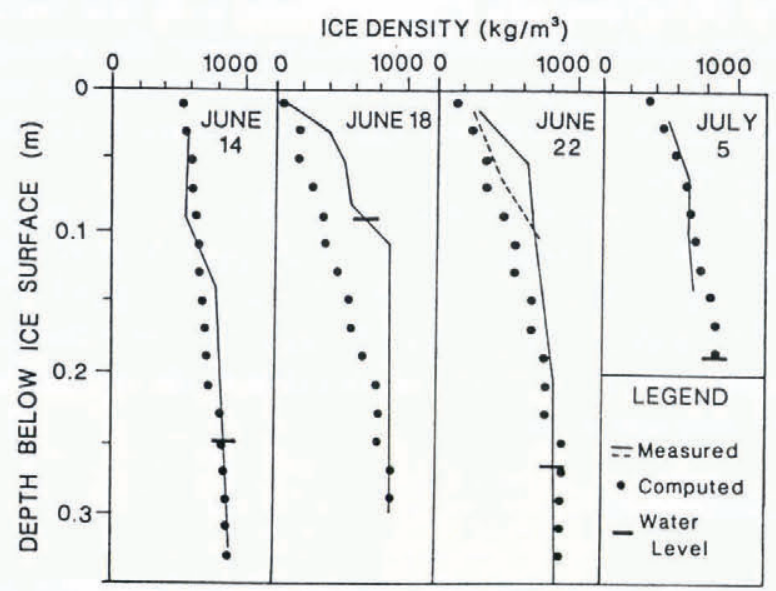

Fig. 8. Observed and calculated ice-density profiles.

Occasional measurements showed that the density of the surface ice varied between these low values and about $600 \mathrm{~kg} \mathrm{~m}^{-3}$. Below the hydrostatic water level, ice density was more uniform at about $800 \mathrm{~kg} \mathrm{~m}^{-3}$ (Fig. 8) but, late in the melt period, density values ranged from 620 to $810 \mathrm{~kg} \mathrm{~m}^{-3}$.

Ice-density profiles altered by internal melt influenced the position of the hydrostatic water level (Fig. 7). The initial decrease in near-surface ice density allowed the ice cover to float higher, thus increasing the distance from the ice surface to the water level. Later, as the ice cover thinned, the hydrostatic water level moved closer to the ice surface.

\section{Albedo}

Internal melt influenced the ice albedo through changes in ice density and the hydrostatic water level. Increased surface porosity raised the albedo of bare ice from about 0.15 to 0.5 . However, remnant snow and basal ice melting at the measurement sites masked this effect, causing it to appear as only a slight dip in the albedo (Fig. 3). A maximum of 0.56 was reached when the hydrostatic water level was at its lowest beneath the ice surface, and when the surface ice reached minimum densities. Thereafter, albedo declined in response to thinning of the ice above the water level and fell to a minimum of 0.10. Superimposed on this general trend were fluctuations in albedo caused by changes in the ice density of the surface layers. A prominent albedo decrease in late June (Fig. 3), from 0.45 to 0.20 , was due to melt removal of the $c$-axis vertical crystals which had previously been protecting the underlying $c$-axis horizontal crystals from internal melting. The ice darkened considerably as this denser, less-porous ice emerged, and this confirmed Knight's (1962) observation that ice-crystal orientation may influence the albedo. In the next few days, the albedo increased to 0.30 in response to internal melt but higher ice densities prevented it from returning to the earlier values.

\section{MODELLED RESULTS}

\section{Ice-cover energy fluxes}

Equations (3)-(17) were used to calculate the energy fluxes and the daily totals are presented in Figure 9. The absorbed shortwave radiation, which provided 42 (1980) and 41 (1981) \% of the energy, was greatest in the early melt period when the ice cover and the porous surface layer were thickest. Both the sensible- and latent-heat fluxes showed an increasing trend throughout the melt period as the atmosphere warmed and became more humid but, on occasions, these could be slightly negative. Sensible-heat flux accounted for 43 and $38 \%$ of the energy received by the surface in 1980 and 1981, respectively, while the latent-heat flux provided 6 and $12 \%$. Of the total surface energy, $13(1980)$ and 17 (1991) $\%$ was used to support the net loss of longwave radiation, while 83 and $87 \%$ was consumed by ice melt. The calculated heat flux from the water was relatively small and increased gradually during the decay period as the water warmed. The heat added to the ice surface by rain was insignificant.

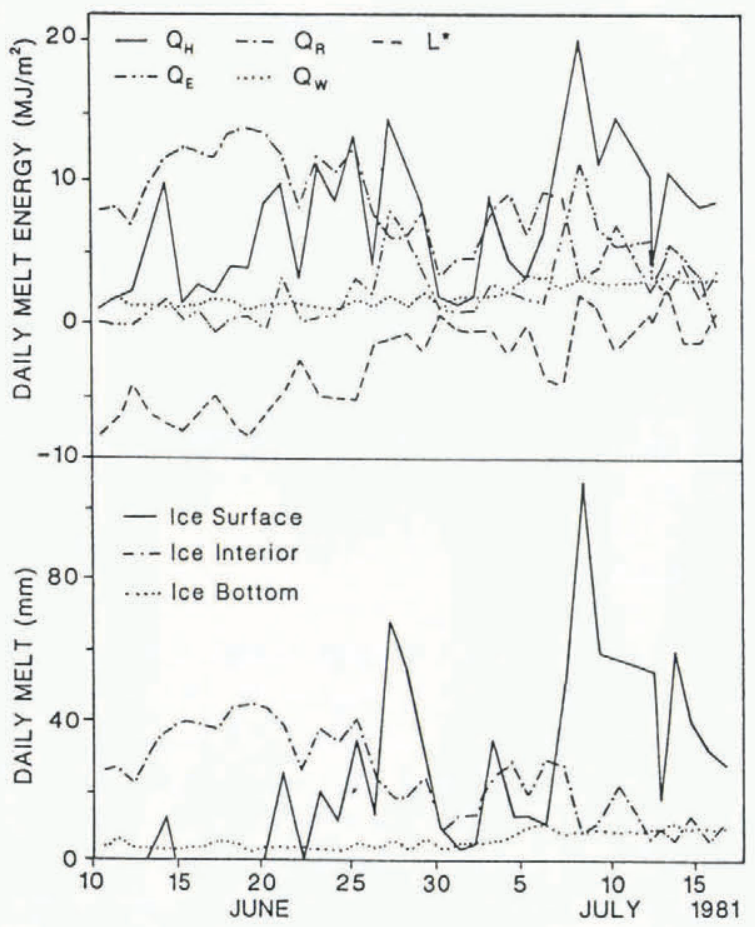

Fig. 9. Calculated daily energy fluxes and ice-melt components (in water-equivalent units).

\section{Calculated ice-melt components}

The heat fluxes were partitioned into components of melt energy expended on the surface, the ice bottom and inside the ice (Fig. 9). The bulk of the energy was consumed by internal melt, averaging $49 \%$ of the melt energy in both years. The maximum calculated daily melt rates were $49 \mathrm{~mm} \mathrm{~d}^{-1}$ in 1980 and $45 \mathrm{~mm} \mathrm{~d}^{-1}$ in 1981 but, by the end of the melt period, internal melt declined to approximately $15 \mathrm{~mm} \mathrm{~d}^{-1}$.

Surface melt accounted for $39 \%$ of the total in 1980 and $40 \%$ in 1981 . Surface melt was limited early in the 
melt period due to large longwave radiation losses, but later it became the largest melt component as the sensibleheat-flux contribution increased. In 1980, the maximum daily surface melt was $113 \mathrm{~mm}$ which was similar to the $108 \mathrm{~mm}$ peak value of 1981 .

Ice-bottom melt was the smallest in magnitude, accounting for 10 and $12 \%$ of the total melt energy in 1980 and 1981.

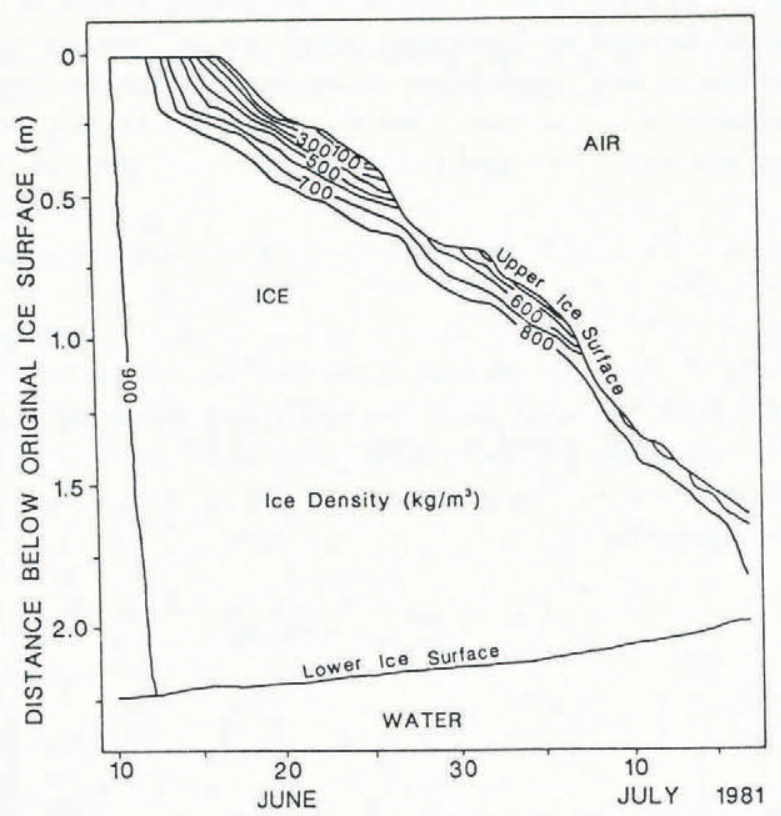

Fig. 10. Calculated ice-density isopleths for the Small Lake ice cover. The reference datum is the original ice surface and the upper and lower ice surfaces were obtained from the cumulative computed melt.

\section{COMPARISON OF OBSERVED AND COMPUTED RESULTS}

\section{Internal melt}

Changes in ice-skeleton density reflect the amount of internal melt. As shown in Figure 10, the modelled ice density remained above $800 \mathrm{~kg} \mathrm{~m}^{-3}$ throughout most of the study period, except in the surface layers above the hydrostatic water level where densities less than $100 \mathrm{~kg} \mathrm{~m}^{-3}$ were attained. Throughout the melt period, ice density in this layer fluctuated in response to the amount of radiation absorbed and the surface-ablation rate. Early in the melt period and at the beginning of July, surface melt was relatively small and internal melting greatly reduced the density. When sensible-heat flux increased in late June and mid-July, the low-density surface layers were melted faster than internal melt could replace them and density increased to about 600$700 \mathrm{~kg} \mathrm{~m}^{-3}$ during these times.

The observed and computed density profiles for the upper $0.35 \mathrm{~m}$ of the ice cover are plotted in Figure 8 . These profiles compared very well at the beginning (14 June) and towards the later part ( 5 July) of the decay period. On 18 June, the computed values correctly estimated the ice density at the surface and at depth $(0.3 \mathrm{~m})$ but they underestimate the density in the central part by as much as $50 \%$. This discrepancy was due to the observed hydrostatic water level being $0.2 \mathrm{~m}$ closer to the surface than modelled, causing the ice in the model to absorb more radiation because it was above the hydrostatic level for a longer period. While the model overestimated the hydrostatic water level by $0.05 \mathrm{~m}$ in this case, the sampling site was also located in an area where the ice surface was depressed $0.15 \mathrm{~m}$ below the average level. The fit improved substantially on 22 June and was close to or within the expected accuracy of the observations.

Near the end of the melt period, the computed results suggest that the mean ice density was approximately 780 $800 \mathrm{~kg} \mathrm{~m}^{-3}$ (Fig. 10). Ice-core densities averaged 720 $\mathrm{kg} \mathrm{m}^{-3}$ with a range of $620-810 \mathrm{~kg} \mathrm{~m}^{-3}$. The difference suggests that more melt was occurring in the ice interior than was computed.

\section{Surface melt}

A comparison of the daily computed and observed ice ablation for the upper surface in 1981 shows that over half of the points lay outside the $20 \%$ error limits. Part of this can be attributed to field-measurement errors. Muller and Keeler (1969) suggested that these measurement errors are largely offsetting and become less important over longer periods. However, large short-term errors may cause significant departures in the cumulative values. For example, the $28 \%$ error by the model for 1981 was due to overestimation of surface ablation during three periods, each lasting about $2 \mathrm{~d}$ (Fig. 11). Each time a major deviation occurred in Figure 11, plotting of the computed curve was discontinued and then restarted at the next measured cumulative surface-ablation point. In the first period, 18-21 June, ice density was probably underestimated, resulting in an overestimate of ablation. During the last two periods (26-27 June and 7-8 July), wind-speeds approached $10 \mathrm{~m} \mathrm{~s}^{-1}$, causing overestimations of sensible- and latent-heat fluxes. When data from these three periods were ignored (dashed line in Figure 11), the measured and computed values became comparable.

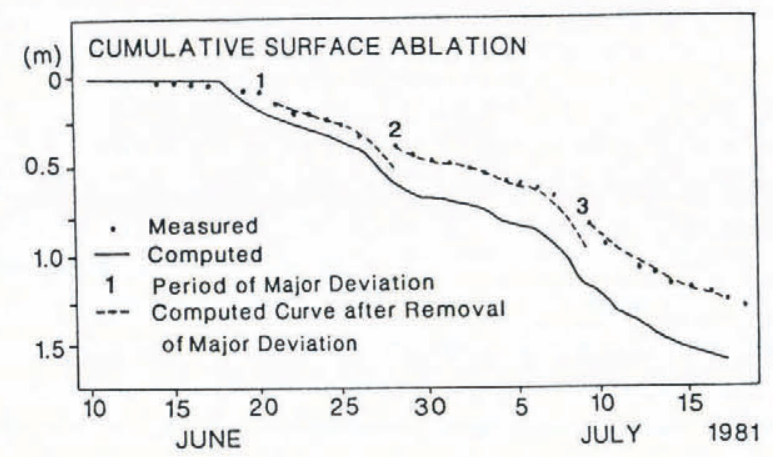

Fig. 11. Measured and computed cumulative ablation at the upper ice surface. The dashed lines represent segments of the computed curve that were restarted at an observed value after a period of major deviation.

\section{Bottom melt}

The melt at the bottom of the ice cover is the least significant of the three melt components. The cumulative 
melt and the calculated melt for 1981 compared favourably (Fig. 12), with the differences rarely exceeding $20 \mathrm{~mm}$ until early July. Beyond that point, the model underestimated systematically due to circulation of the lake water (thus invalidating the assumption of still water used in the model) and the movement of the ice cover about the lake.

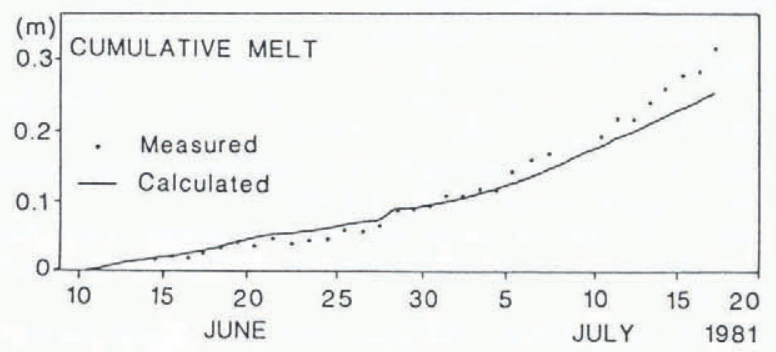

Fig. 12. Measured and calculated cumulative melt from the lower ice surface.

\section{DISCUSSION}

Arctic lake-ice cover tends to be thicker and colder than that in the sub-Arctic, alpine or temperate regions and is composed primarily of very large, interlocking crystals. Melt commences less than 1 month before the summer solstice, so the ice cover experiences $24 \mathrm{~h}$ of daylight during decay. The surface-radiation balance is usually positive and, since the ice is not subject to night-time refreezing, melt is essentially continuous during the 6 weeks (or longer) of decay.

During the melt period, the porosity of the surface layers increased greatly and ice densities lower than $100 \mathrm{~kg} \mathrm{~m}^{-3}$ were achieved. Ice albedo peaked with minimum ice density and decreased along with ice porosity. Reduction in the surface-ice density contributed greatly to the lowering of the ice surface, which accounted for approximately $75 \%$ of the change in ice thickness. Melt at the bottom of the ice cover was initially very small but, when the ice fragmented at the end of the decay period, rates of more $100 \mathrm{~mm} \mathrm{~d}^{-1}$ were observed.

The one-dimensional ice-melt model described above satisfactorily predicted the rate of ice-thickness decrease for almost $80 \%$ of the measurement period. The deviations of the model results from the observed conditions can be attributed to inadequacies in both the meteorological variables and the parameterization of the model. In a sensitivity analysis, Greene and Outcalt (1985) determined that their river-ice growth and decay model was less sensitive to the meteorological variables than the extinction coefficient, surface roughness and albedo parameters. Improvements in the estimation of these would increase the accuracy of the model.

The bulk aerodynamic-transfer approach to calculating turbulent-heat transfer is relatively easy to employ and it is commonly used over melting surfaces (Moore, 1983; Munro, 1989). Comparisons with alternative microclimate methods have shown that it performs well (Hay and Fitzharris, 1988; Munro, 1989) but, when the atmospheric and ice-surface conditions deviate from the assumptions required for this approach, the magnitudes of the errors thus created are not known (Moore, 1983).
Such violations of assumptions include the failure of the boundary layer to develop to the height of the instrumentation, the departure from log-linear wind profiles and changes in the aerodynamic roughness of the ice. Resultant errors in the computations of sensible and latent heat could have caused large differences between observed and computed surface melt that occurred on several occasions during the study seasons.

As presently structured, the model is applicable to Arctic lakes which do not completely freeze to their bed. Through modelling, it is possible to partition ice decay into different components. When the overprediction of surface ablation and the underestimation of ice-bottom melt are accounted for, about one-half of the total energy $(52 \%)$ was spent on internal melting because of the concentration of radiant energy in the upper part of the ice. The importance of internal melt therefore cannot be ignored in Arctic lake-ice melt models. Approximately $33 \%$ of the melt energy was expended at the upper ice surface and about $15 \%$ was used for ice-bottom melting during the study period. However, episodes of rapid bottom melt occurred at the end of the melt period, suggesting that this component may become more important when the ice cover fragments and moves frequently.

\section{ACKNOWLEDGEMENTS}

This research was supported by funding from the Natural Sciences and Engineering Research Council of Canada, The Arctic Institute of North America and the Northern Scientific Training Program. Generous logistic support was provided by the Polar Continental Shelf Project, Department of Energy, Mines and Resources. We should like to thank Mr P. Steer, Mr P. Low and Mr D. Orr for their assistance in the field and Mr R. Welch for his cartography.

\section{REFERENCES}

Adams, W. P. 1981. Snow and ice on lakes. In Gray, D. M. and D. H. Male, eds. Handbook of snow: principles, processes, management and use. Toronto, Pergamon Press Canada Ltd., 437-474.

Alestalo, J. 1980. Systems of ice movement on Lake Lappajärvi, Finland. Fennia, 158(1), 27-39.

Ashton, G. D. 1983. Lake ice decay. Cold Reg. Sci. Technol., 8(1), 83-86. Ashton, G. D. 1985. Deterioration of floating ice covers. J. Energy Resour. Technol., 107(2), 177-182.

Barnes, D. F. 1960. An investigation of a perennially frozen lake. Bedford, MA, Air Force Cambridge Research Laboratory. (Air Force Surveys in Geophysics 129.)

Bilello, M. A. 1980. Maximum thickness and subsequent decay of lake, river and fast sea ice in Canada and Alaska. CRREL Rep. 80-6.

Bolsenga, S.J. 1978. Photosynthetically active radiation transmittance through ice. Ann Arbor, Michigan, July, Great Lakes Environmental Research Laboratory, U.S. Department of Commerce. (NOAA Technical Memorandum ERL-GLERL-18.)

Bolsenga, S.J. 1981. Radiation transmittance through lake ice in the 400-700 nm range. f. Glaciol., 27(95), 57-66.

Carson, C. E. and K. M. Hussey. 1960. Hydrodynamics in three Arctic lakes. J. Geol., 68(6), 585-600.

Goldman, C. R., D. T. Mason and J. E. Hobbie. 1967. Two Antarctic desert lakes. Limnol. Oceanogr., 12(2), 295-310.

Greene, G. M. and S. I. Outcalt. 1985. A simulation model of river ice cover thermodynamics. Cold Reg. Sci. Technol., 10(3), 251-262. 
Grenfell, T. C. and G.A. Maykut. 1977. The optical properties of ice and snow in the Arctic Basin. 7. Glaciol., 18(80), 445-463.

Grenfell, T.C. and D. K. Perovich. 1981. Radiation absorption coefficients of polycrystalline ice from $400-1400 \mathrm{~nm}$. F. Geophys. Res., 86(C8), 7447-7450.

Grenfell, T. C. and D. K. Perovich. 1984. Spectral albedos of sea ice and incident solar irradiance in the southern Beaufort Sea. F. Geophys. Res., 89(C3), 3573-3580.

Hay, J.E. and B. B. Fitzharris. 1988. A comparison of the energybalance and bulk-aerodynamic approaches for estimating glacier melt. F. Glaciol., 34(117), 145-153.

Hobbie, J.E. 1973. Arctic limnology: a review. In Britton, M.E., ed. Alaska Arctic tundra. Arc. Inst. North Am. Tech. Pap. 25, 127-168..)

Hobbs, P. V. 1974. Ice physics. Oxford, Clarendon Press.

Irvine, W. M. and J. B. Pollack. 1968. Infrared optical properties of water and ice spheres. Icarus, 8(2), 324-360.

Knight, C. A. 1962. Studies of arctic lake ice. F. Glaciol., 4(33), 319-336.

Lettau, H. 1969. Note on aerodynamic roughness-parameter estimation on the basis of roughness element description. F. Appl. Meteorol., 8, 828-832.

Moore, R.D. 1983. On the use of bulk aerodynamic formulae over melting snow. Nord. Hydrol., 14(4), 193-206.

Müller, F. and C.M. Keeler. 1969. Errors in short-term ablation measurements on melting ice surfaces. F. Glaciol., 8(52), 91-105.

Munro, D.S. 1989. Surface roughness and bulk heat transfer on a glacier: comparison with eddy correlation. F. Glaciol., 35(121), 343-348.

Perey, F. G.J. and E. R. Pounder. 1958. Crystal orientation in ice sheets. Can. J. Phys., 36(4), 494-502.

Price, A.G. and T. Dunne. 1976. Energy balance computations of snowmelt in a subarctic area. Wat. Resour. Res., 12(4), 686-694.
Ramseier, R. O. and R.J. Weaver. 1975. Floating ice thickness and structure determination - heated wire technique. Ottawa, Environment Canada. Water Resources Branch. (Technical Bulletin 88.)

Roulet, N.T. 1981. Variability of the quality and quantity of light penetrating a winter lake cover. (M.Sc. thesis, Trent University.)

Schindler, D. W., H. E. Welch, J. Kalff, G.J. Brunskill and N. Kritsch. 1974. Physical and chemical limnology of Char Lake, Cornwallis Island ( $75^{\circ} \mathrm{N}$ Lat.). J. Fish. Res. Board Can., 31(5), 585-607.

Scott, J. T. and R. A. Ragotzkie. 1961. Heat budget of an ice-covered inland lake. Madison, WI, University of Wisconsin. Department of Meteorology. (Technical Report 6.)

Shaw, J.B. 1965. Growth and decay of lake ice in the vicinity of Schefferville (Knob Lake), Quebec. Arctic, 18(2), 123-132.

Wake, A. and R. R. Rumer, Jr. 1979. Modeling ice regime of Lake Erie. ASCE J. Hydraul. Div., 105(HY7), 827-844.

Williams, G.P. 1965. Correlating freeze-up and break-up with weather conditions. Can. Geotech. F., 2(4), 313-326.

Williams, G. P. 1968. Freeze-up and break-up of fresh water lakes. Associate Committee on Geotechnical Research. Technical Memorandum 92, 203-215.

Woo, M.-K. and R. Heron. 1981. Occurrence of ice layers at the base of High Arctic snowpacks. Arct. Alp. Res., 13(2), 225-230.

Woo, M.-K., R. Heron and P. Steer. 1981. Catchment hydrology of a High Arctic lake. Cold Reg. Sci. Technol., 5(1), 29-41.

The accuracy of references in the text and in this list is the responsibility of the authors, to whom queries should be addressed.

MS received 30 November 1992 and in revised form 23 June 1993 